\title{
A Study on Twill Damask of the Song and Liao Dynasties
}

\author{
Chunhua $\mathrm{Gu}^{1} \&$ Yanghua Kuang ${ }^{2}$ \\ ${ }^{1}$ School of Fashion \& Art Design, Donghua University, Shanghai, China \\ ${ }^{2}$ College of Textiles \& Clothing, Jiangnan University, Wuxi, China \\ Correspondence: Chunhua Gu, College of Textiles \& Fashion, Anhui Polytechnic University, Beijing Middle \\ Road, Wuhu 241000, Anhui Province, China. Tel: 86-153-9532-1325. E-mail: gchguchunhua@126.com
}

Received: September 17, 2013 Accepted: October 31, 2013 Online Published: December 31, 2013

doi:10.5539/ass.v10n1p66 URL: http://dx.doi.org/10.5539/ass.v10n1p66

\begin{abstract}
Based on abundant archeological evidences, this paper systematically discusses the weave and motif of twill damask of the Song and Liao dynasties. Categorized according to the weave, twill damask of the Song and Liao dynasties can be described as: twill in same direction, twill in different direction, twill with weft floats and brocaded twill; and the motifs adopted by twill damask of the Song and Liao dynasties mainly contain geometrical motif, floral motif, fauna motif (including birds and animals) and figural motif (including boys at play and Taoists).
\end{abstract}

Keywords: twill damask, Song and Liao dynasties, weave structure, pattern

Twill damask appeared two thousand years ago and had it's hey day in the Tang dynasty. In the Song and Liao dynasties twill damask remained in vogue, which can be proved by a lot of archeological evidences of this period. The weave and motif of twill damask of Song and Liao dynasties are going to be systematically studied below.

\section{The Weave of Twill Damask of the Song and Liao Dynasties}

Twill damask is a monochrome woven silk, with pattern and ground in different weave structures (Zhao Feng, 2005). In the Song dynasty, twill damask was produced on a large scale in workshops run by the government such as Lingjinyuan or Wensiyuan. Twill damask, of different kinds, was widely used for official robes, imperial edicts, monk's or nun's certificates and calligraphy or painting mounting. According to archeological evidences, twill damask in the Song and Liao dynasties is similar to that in the Tang dynasty in weave but more abundant in category. Twill damask in the Song and Liao dynasties mainly includes the following categories: twill in same direction, twill in different direction, twill with weft floats and brocaded twill.

\subsection{Twill in Same Direction}

\subsubsection{Twill Damask with Same Unit in Same Direction}

Theoretically, any difference between the three basic elements, i.e. unit, direction, face (domination of warp or weft), of twill weave between pattern and ground will form a damask pattern. Twill damask with same unit in same direction but different in face between pattern and ground first appeared in the Liao dynasty. It includes two types: $1 / 5$ or $5 / 16$-end twill and $1 / 3$ or $3 / 14$-end twill. The former is more common and has got many examples from Yelüyuzhi's tomb, mostly in a weave of $1 / 5$ twill for pattern on a ground of $5 / 1$ twill. Some times, the direction of twill can be changed, for example, the twill damask with paired phoenixes enclosed in roundels consisting of scrolled clouds and the twill damask with boys at play among peonies and running rabbits in a lozenge frame both show a diamond effect created by symmetrical chevron twill.

\subsubsection{Twill Damask with Different Units in Same Direction}

Damask with twill in the same direction first appeared in the Tang dynasty, 3-end and 6-end twill damask were common, which mostly were twill with different units in same direction. They were still favored in the Song and Liao dynasties, mostly in a structure of $1 / 5$ twill and 2/1 twill for pattern or ground, such as the twill damask with lions enclosed in entwined flowers and the twill damask with flowers, fruits and boys both unearthed from Hejiazao in Hengyang, Hunan province; the twill damask with roundel enclosing confronted peacocks, the twill damask with big medallions, the twill damask with clouds and the twill damask with a Taoist figures, clouds and cranes all unearthed from Yelüyuzhi's tomb (Zhao, 2004). 


\subsection{Twill in Different Directions}

\subsubsection{Twill Damask with Same Unit in Different Directions}

Twill damask with same unit in different directions includes damask with 4-end twill in different directions and damask with 6-end twill in different directions.

4-end twill in different directions was first found on the damask unearthed from the tombs of the Han and Jin dynasties. It was popular in the Tang dynasty and remained to be favored in the Song and Liao dynasties, for example, the twill damask with lozenge pattern unearthed from Hejiazao and the twill damask with entwined flowers unearthed from Zhou Yu's tomb are both in a weave of 4-end warp-faced S twill for pattern on a ground of 4-end weft-faced Z twill. Damask with twill in different directions were also found in Huang Sheng's tomb in Fujian province, for example, the twill damask with peonies, lotus and plum blossoms and the twill damask with peonies and Begonia flowers are both in a weave of 3/1 weft-faced twill for pattern on a ground of $1 / 3$ warp-faced twill. Generally, pattern created by twill in different direction is more vivid.

Damask with 6-end twill in different directions appeared later, the twill damask with cranes enclosed in entwined flowers unearthed from Hejiazao is in a weave of $1 / 5 \mathrm{~S}$ twill for pattern on a ground of $5 / 1 \mathrm{Z}$ twill, and the twill damask with peonies, lotus and boys is in a weave of $5 / 1 \mathrm{Z}$ twill for pattern on a ground of $1 / 5 \mathrm{~S}$ twill. However, twill damask in this weave became common in the Liao dynasty.

\subsubsection{Twill Damask with Different Units in Different Directions}

Twill damask of this sort is different in unit, direction and face between pattern and ground. It was first found in the tomb of the Liao dynasty, in a weave of $1 / 7$ weft-faced twill for pattern on a ground of 3/1 warp-faced twill for ground. A few examples have been found, including the damask with a deer holding a ribbon running in mountains and the damask with four wild geese in a lozenge frame both unearthed from Yelüyuzhi's tomb.

\subsection{Twill with Weft Floats}

A number of twill damask with pattern formed by floating weft has been in the tombs of the Song dynasty. Actually, the technique of using floating weft to form pattern is quite easy, and in the Tang dynasty it was adopted by twiwll damask. There are two types of twill with weft floats: weft floats for pattern on a ground of twill, for example, a till damask unearthed from the tombs of the Western Xia regime in Ningxia province shows a $\mathrm{H}$ pattern created by floating weft on a ground of $2 / 1$ twill; the other has floating weft woven with two shuttles, therefore floating weft is much thicker than foundation weft (Zhao, 2005), such as the damask with rosettes and diamonds unearthed from Hejiazao and the damask with catharanthus roseus unearthed from Huang Sheng's tomb.

\subsection{Twill with Supplementary Weft and Twill Brocaded Supplementary Weft}

Since the Song and Liao dynasty, the technique of weaving supplementary weft yarns of different colors into twill foundation weave to form pattern has been used. When discontinuous supplementary weft yarns are woven in to the foundation weave of twill in specific areas required by the pattern, the textile is named brocaded twill. Brocaded twill of the Song and Liao dynasties include two categories: one with supplementary weft yarns in a single color, the other with supplementary yarns of different colors. As a brocaded textile, the latter one is more typical and has examples from Yelüyuzhi's tomb, such as brocaded twill with lions, birds and flowering trees and brocaded twill with mallow flowers, paired doves and butterflies.

\subsection{Summary}

The weave of the twill damask discussed above suggests that twill damask of the Song and Liao dynasties was developed from twill damask of the Tang dynasty, but it was more abundant in category. Damask in new weave structure such as twill damask with same unit in same direction and twill damask with different units in same direction have been found in the tomb of the Liao dynasty and twill damask in compound weave with supplementary weft began popular in the Song and Liao dynasties.

\section{The Motif Adopted by Twill Damask of the Song and Liao Dynasties}

Geometrical motif was very popular on the twill damask of the Song dynasty, here are the reasons: firstly, rationalistic Confucianism was highly valued in the Song dynasty, and geometrical motif was considered to be rational both in composition and meaning; Secondly, calligraphy and painting had greatly developed in the Song dynasty, and textile with geometrical pattern was adapt for mounting; Thirdly, leaves interspersed with geometrical motifs such as swastikas or ribbons became a favored pattern during this period. Besides geometrical motifs, birds or butterflies in combination with flowers were also favored in the Song and Liao dynasties and they mostly have special auspicious meanings. 


\subsection{Geometrical Motif}

Geometrical motifs on twill damask of the Song dynasty mainly include swastika, glechoma, coin, ribbon, cross and lozenge etc.

In ancient times $\gtrsim$ (swastika) was an auspicious symbol; During the reign of Wu Zetian in the Tang dynasty the pronunciation of $\gtrsim$ was identical to that of Chinese character wan (ten thousand). Swastika is widely adopted by silk, sometimes appear alone and sometimes appear in groups. Linked swastikas have an auspicious meaning: to last forever or to be endless. The pattern on a twill damask unearthed from Zhou Yu's tomb, of the Southern Song dynasty, in Jintan, Jiangxi province shows swastikas filled in glechomas, with an effect similar to relief. Glechoma refers to the square-shaped part in the centre of a coin, for example, the pattern on twill damask unearthed from Zhou Yu's tomb is glechoma. Besides, glechoma is also interspersed with large geometrical pattern in Latticework.

Coin pattern has developed from link-pearls and roundels of the Tang dynasty and was very popular in the Song dynasty. It consists of linked circles, with big circles in the centre and small circles surrounded, and then interspersed with birds, animals or geometrical patterns. Coin pattern has different categories: the one consists of a single circle was called Panqiu pattern; the one consists of six linked circles was called Culiuqiu pattern, the one filled with other patterns in the centre was called Tianhuaqiu pattern. Ribbon pattern was also favored in this period and ribbon often consists of ball. A twill damask unearthed from Yelüyuzhi's tomb of the Liao dynasty shows big balls made of ribbons, which are also linked with ribbons. Ribbon ball on another piece of twill damask unearthed from this tomb is even larger in size (Figure 1).

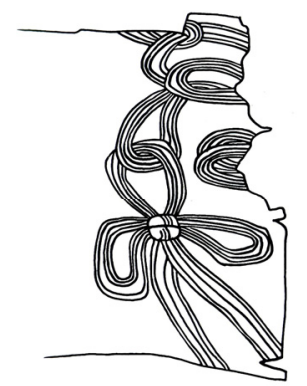

Figure 1. Ribbon pattern on twill damask (detail, reconstructed pattern), Liao Dynasty

The composition of lozenges is quite flexible. Lozenges can be linked in pairs and with some parts overlapped; small lozenges could be filled in big lozenges, such as the pattern on a twill damask of the Liao dynasty depicted in Figure 2 (Zhao, 2004); lozenges also can be used as frame, for example, the pattern on a twill damask unearthed from Yelüyuzhi's tomb depicted in Figure 3 (Huang \& Chen, 2002) consists of lozenges filled with flowers.

Cross pattern is also found on twill damask unearthed from tombs of the Liao dynasty.

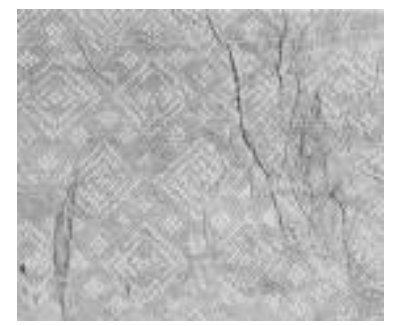

Figure 2. Lozenges on twill damask, Liao dynasty

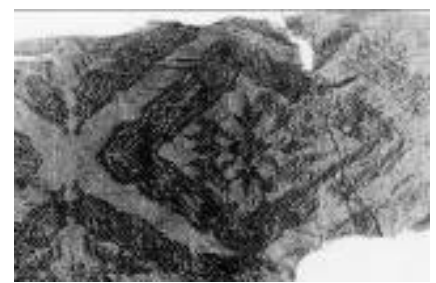

Figure 3. Lozenges filled with flowers on twill damask, Liao dynasty 


\subsection{Floral Motif}

Since the Tang dynasty, more floral motif had been used for silk; and in the Song and Liao dynasties, floral motif became even more popular, which can be proved by pattern on twill damask. The floral motif on twill damask mainly includes floral roundel, scroll, plum blossom and peony etc. Sometimes it appears alone, sometimes it is interspersed with birds or butterflies.

Here are some examples from tombs of the Liao dynasty: a short-sleeved robe made of twill damask from Daiqintala shows small four-petalled roundels; another skirt of twill damask also from this tomb has identical floral roundels on a yellow ground; a twill damask unearthed from Yelüyuzhi's tomb bears big medallions consisting of four-petalled flowers enclosed in linked circles, with quatrefoils in between medallions (there are only two medallions across the weft direction, therefore the medallion is quite large in size).

Persimmon calyx pattern seems like persimmon calyx, consisting of four heart-shaped calyxes arranged in the shape of a cross. It was favored in the Tang and Song dynasties and widely used for twill damask, samite and dyed silk (Zhou \& Gao, 1996). The pattern on a piece of twill damask unearthed from Yelüyuzhi's tomb is an example of persimmon calyx pattern, with flowers enclosed in the centre.

Plum blossom was also a common motif in the Song and Liao dynasties. Many twill damask of the late Liao dynasty unearthed from the white pagoda in Qingzhou bear plum blossoms; the spray with plum blossoms depicted in fig.4 is an example from this site. Plum blossom is also widely adopted by twill damask of the Southern Song dynasty unearthed from Huang Sheng's tomb; some times plum blossom appears with other patterns, for example, the pattern consists of plum blossoms and balls.

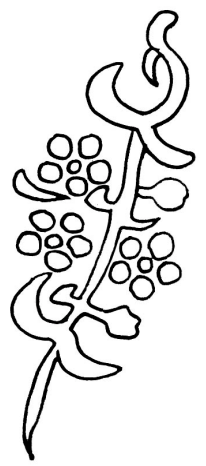

Figure 4. Sprays with plum blossoms on twill damask (detail, reconstructed pattern), Liao dynasty

Few twill damask show peony, three examples are: a twill damask with a single roundel consisting of peonies and peacocks unearthed from Yelüyuzhi's tomb, a twill damask with peonies unearthed from Huang Sheng's tomb, and a twill damask of the Northern Song dynasty with peonies, mallow flowers, lotus and boys unearthed from Hejiazao.

Mallow flower occasionally appears on twill damask, for example, a robe made of brocaded twill unearthed from Yelüyuzhi's tomb bears confronting birds and butterflies under a mallow flowering tree, and the piece from Hejiazao previously discussed shows a pattern of mallow flowers, peonies, lotus and boys.

Entwining flowers began to appear on twill damask in the Song dynasty, such as the piece with mallow flowers, peonies, lotus and boys discussed above, entwining flowers are also in the combination with animals, usually with animals enclosed in entwining flowers, for example, the pattern on a twill damask unearthed from Hejiazao consists of lions enclosed in entwining flowers, the pattern on a twill damask also from this tomb consists of cranes enclosed in entwining flowers.

\subsection{Fauna Motif}

Fauna motifs mainly include birds and animals. Birds contain phoenix, peacock, eagle, wild goose, dove, crane, mandarin duck, and egret etc. Animals contain lion, deer and rabbit etc. On twill damask animal motifs usually combine with flowers.

\subsubsection{Birds}

Peacocks on twill damask of the Liao dynasty are mostly in the gesture of flying or standing. A piece of twill damask unearthed from Yelüyuzhi's tomb shows flying peacocks in a frame of coin. Another piece of twill 
damask from this tomb bears confronted peacocks with spays in beaks standing on a pedestal under a peony tree enclosed in a roundel (Figure 5).

The Khitans used to hunt wild goose in rivers or ponds in spring and wild goose pattern is quite popular in the Liao dynasty. It mainly includes two kinds: standing wild goose and wild goose with ribbon in its beaks. The pattern on a piece of twill damask unearthed from Yelüyuzhi's tomb is standing wild goose, in a realistic style and with two wings spread (Figure 6). Wild goose often combines with clouds, for example, the pattern on a twill damask of the Liao dynasty shows four flying wild geese holding flowers enclosed in a circle consisting of scrolled clouds.

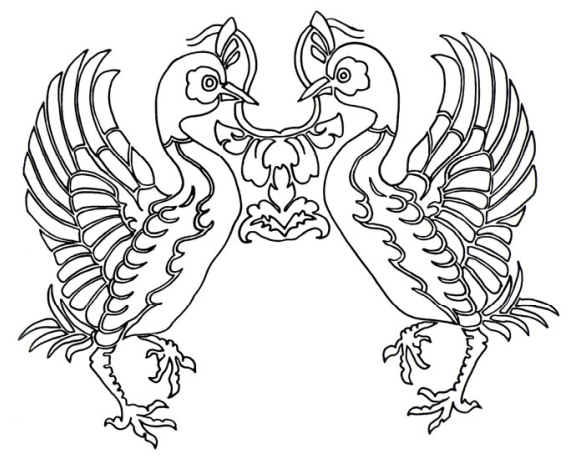

Figure 5. Roundel with confronted peacocks on twill damask (detail, reconstructed pattern), Liao dynasty

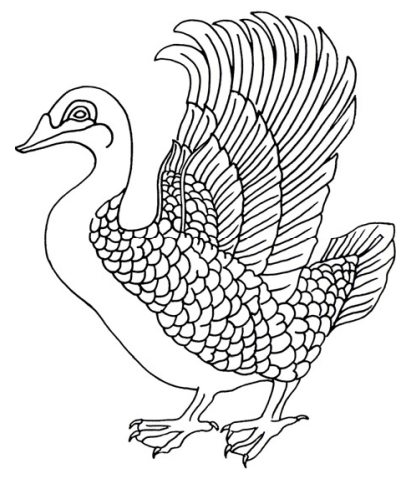

Figure 6. Standing wild goose on twill damask (detail, reconstructed pattern), Liao dynasty

Phoenix pattern is widely used for silk of the Liao dynasty. Phoenix pattern of the Liao dynasty is quite different to that of other dynasties in tail and crest. It also includes flying phoenix and standing phoenix. The pattern on a brocaded twill unearthed from Xiaomurimu (in Keerqinzuo banner, Zhelimu, Inner Mongolia) shows roundels consisting of two flying phoenixes(Figure 7), whirling head to tail in a circle on a blue ground also of flying phoenixes. Another example from this tomb is twill damask with paired phoenixes enclosed in circles consisting of scrolled clouds on a ground of diamonds. A twill damask from Yelüyuzhi's tomb bears four flying phoenixes in roundels on a ground of waves (Figure 8). Phoenix seldom appears with dragon, one example is a piece of twill damask unearthed from Yelüyuzhi's tomb.

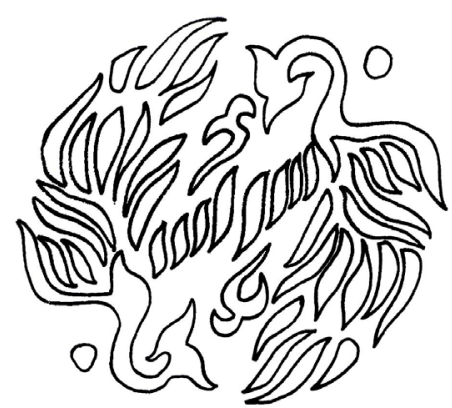

Figure 7. Phoenixes on brocaded twill (detail, reconstructed pattern), Liao dynasty 


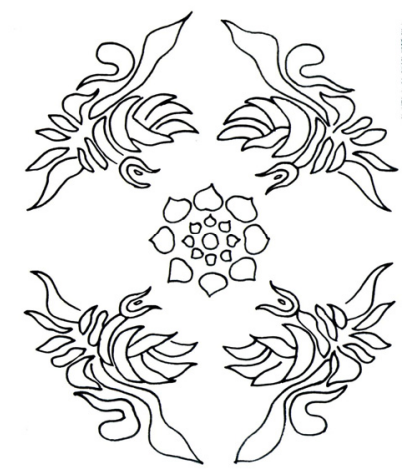

Figure 8. Phoenix roundels on twill damask (detail, reconstructed pattern), Liao dynasty

Other birds such as dove, crane, mandarin duck and egret are mostly flying among flowers, leaves and clouds, or standing under trees. They are varied in form and size, and often interspersed with butterfly or bee. For example, a robe made of brocaded twill unearthed from Yelüyuzhi's tomb shows two white doves under a mallow flowering tree, with butterflies, bees and other birds flying around. Another piece of brocaded twill bears birds with ribbons, butterflies and bees flying among flowers and leaves.

\subsubsection{Animals}

The Khitans originates from a place where there are many deer; Therefore, deer is a common motif on twill damask of the Liao dynasty. Deer on twill damask unearthed from Yelüyuzhi's tomb are mostly in the gesture of running, for example, a twill damask shows a deer holding a ribbon running in mountains, with an influence from the Central Asia (Figure 9), another example is a twill damask with winged running deer in different gestures, paired flying eagles and flowers enclosed in a frame of coin. Khitans and Jurchens like hunting, therefore, hunting scene is widely used for textile and embroidery, and in this case, eagle often appears together with deer or rabbit.

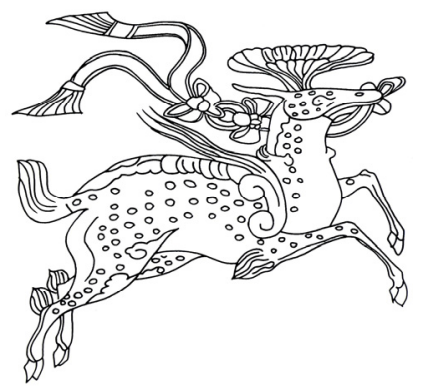

Figure 9. Deer holding a ribbon on twill damask (detail, reconstructed pattern), Liao dynasty

Lion pattern on twill damask of the Liao dynasty is lovely, some times in flowers or leaves, such as lion roundels on a wave ground on a twill damask unearthed from Yelüyuzhi's tomb (Figure 10), sometimes under a flowering tree, for example, a robe of brocaded twill unearthed from the same tomb shows a large-scaled lion under a big flowering tree (pomegranates), with a necklace round its neck and a ball under its right front foot (Figure 11).

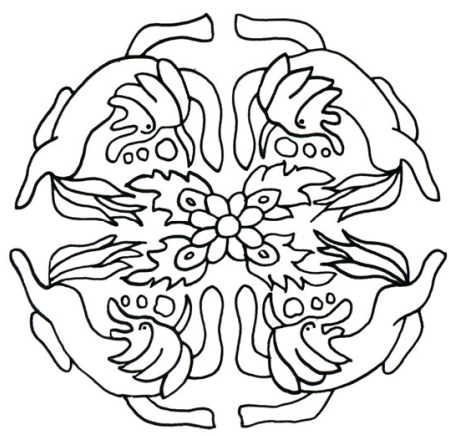

Figure 10. A lion roundel on wave ground on twill damask (detail, reconstructed pattern), Liao dynasty 


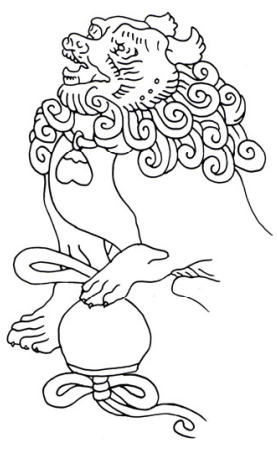

Figure 11. A lion under a flowering tree on brocaded twill damask (detail, reconstructed pattern), Liao dynasty

\subsection{Figural motif}

Figural motif is also adopted by twill damask of the Song and Liao dynasties, usually including boys at play and Taoists.

\subsubsection{Boys at Play}

The image of boy at play is a common motif on the twill damask of the Song and Liao dynasties and has got a lot of archeological evidences, for example, a twill damask unearthed from Yelüyuzhi's tomb shows boys at play among peonies and running rabbits in a lozenge frame, a twill damask unearthed from Hejiazao bears boys playing with sprays, and a twill damask of the Song dynasty also shows boys at play among peonies (Figure 12). Generally, running rabbits appear together with playing boys, such as on a piece unearthed from Yelüyuzhi's tomb.

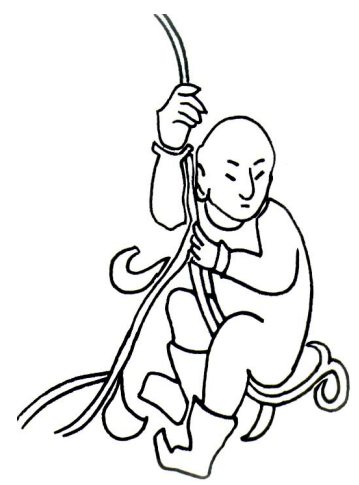

Figure 12. A boy plays with sprays on twill damask (detail, reconstructed pattern), Song dynasty

\subsubsection{Taoists}

Taoist motif is also favored by twill damask of the Liao dynasty. For example, a twill damask unearthed from Yelüyuzhi's tomb shows a woman related to Taoism, wearing Han style robe and crown, holding a feather fan in her right hand, standing on clouds and guided by a flying crane.

\section{Summary}

The style of motif was also developed in the Song and Liao dynasties. Geometrical motifs such as swastika, glechoma, coin, ribbon, cross and lozenge were favored on twill damask of the Song dynasty; floral motifs sometimes interspersed with birds or butterflies in a naturalistic style became even more popular in the Song and Liao dynasties; and lion, deer, eagle, phoenix, peacock, goose and human figure were also used for twill damask of this period.

\section{References}

Huang, N. F., \& Chen, J. J. (2002). 7000 Years of Chinese Silk Technology and Art. Beijing: China Textile \& Apparel Press.

Zhao, F. (2004). Liao Textile \& Costumes. Hong Kong: Muwen Tang Fine Arts Publication Ltd. 
Zhao, F. (2005a). A History of Chinese Silk Art. Beijing: Cultural Relics Press.

Zhao, F. (2005b). General History of Chinese Silk. Suzhou: Suzhou University Press.

Zhou, X., \& Gao, C. M. (1996). Big Dictionary of Chinese Costume. Shanghai: Shanghai Lexicographical Publishing House.

\section{Copyrights}

Copyright for this article is retained by the author(s), with first publication rights granted to the journal.

This is an open-access article distributed under the terms and conditions of the Creative Commons Attribution license (http://creativecommons.org/licenses/by/3.0/). 